Notes and Comments

\title{
Asymmetry of the wing in Drosophila mojavensis sonorensis Castrezana in Pfeiler et al., 2009 (Diptera, Drosophilidae): main versus seasonal host
}

\author{
J. O. Prestes ${ }^{\mathrm{a}}$ (D), M. Costa ${ }^{\mathrm{b}}$ (D), L. P. B. Machado ${ }^{\mathrm{a}, \mathrm{b}}$ (1) and R. P. Mateus $\mathrm{s}^{\mathrm{a}, \mathrm{b} *}$ (D) \\ aUniversidade Estadual do Centro-Oeste - UNICENTRO, Campus CEDETEG, Departamento de Ciências Biológicas, Programa de Pós-Graduação \\ em Biologia Evolutiva, Guarapuava, PR, Brasil \\ 'Universidade Estadual do Centro-Oeste - UNICENTRO, Campus CEDETEG, Departamento de Ciências Biológicas, Guarapuava, PR, Brasil
}

Drosophila mojavensis sonorensis inhabits the Sonora Desert and primarily uses cladodes of the columnar cactus Stenocereus thurberi (Engelm.) Buxb. as host (Pfeiler et al., 2009). However, when available, this subspecies also uses decomposing fruits of cacti of the genus Opuntia (L.) Mill. (known as tunas) as seasonal hosts (Mateus et al., 2019). Therefore, the objective of this study was to test the stressing effect of two semi-natural diets, one from the primary host ( $S$. thurberi cladodes) and another from the seasonal host (Opuntia spp. tunas), on the development of $D$. $m$. sonorensis, using the level of asymmetry of the wings as an index of instability on the development due to the different composition of these diets.

Three populations of D. m. sonorensis, Las Bocas, Nogales and Obregon from Sonora Desert in Mexico, were used in the experiments. Larvae of these populations were transferred to the semi-natural diets ( 10 replicates of 40 larvae for each diet and population). The composition of the diets, the volume used of the diets, and the maintenance conditions of larvae, as temperature, humidity and photoperiodicity, are described in Mateus et al. (2019). Right and left wings of up to 100 adults of each combination of sex $x$ diet $x$ population (totalizing approximately 1,200 flies) were removed, and twelve type I anatomic markers (Figure 1) were inserted in the dorsal region of each wing image (Rohlf, 2015).

The level of wing shape asymmetry was determined by coordinates aligned of Generalized Procrustes Analysis (GPA, Marchand et al., 2003; Lima et al., 2016) as dependent variables in a Procrustes ANOVA, performed using MorphoJ 1.06d (Klingenberg, 2011) and R 3.3.0 (R Development Core Team, 2016) softwares. In this analysis, the individual factor corresponds to the individual variation of shape, and the side factor (right and left) corresponds to directional asymmetry (DA); the interaction between side and individual corresponds to fluctuating asymmetry (FA); and the residue is the error measure, which corresponds to the marking repetitions. Antisymmetry (AS) in the wing shape was analyzed through dispersion charts of the difference between the right and left side of each marker
(Palmer, 1994; Klingenberg and McIntyre, 1998; Palmer and Strobeck, 2003). Procrustes distance between right and left wings of each individual was used as the level of individual net asymmetry NAi (fluctuating + directional) and the global population asymmetry was estimated by the average of the NAi in each population (Marchand et al., 2003).

The Procrustes ANOVA results showed that both semi-natural diets caused instability in the development (Table 1), mostly because of Las Bocas males (Mann-Whitney $U=5,859, p<0.05)$, with the higher proportion of asymmetry being related to FA (Figure 2). There are two possible reasons for these results. First, the diets were not stressful enough as there was no difference in the asymmetry levels between diets and the response of the three populations were similar (excepted in Las Bocas males; see Figure 2). Similar results were already shown in other works that found that the host cactus could exert similar influence in the viability and life history of organisms of different species (Soto et al., 2007, 2008). Costa et al. (2015), in a study on the geographical distribution of $D$. antonietae Tidon-Sklorz \& Sene, 2001, found that despite a variation in the net asymmetry between populations, these presented equivalent levels of fluctuating asymmetry, which were also related with similar responses given by populations when submitted to the same level of stress.

Second, selective pressures exerted by the cladodes and tunas differ along the larval development of the flies, causing a trade-off between the characteristics of life history and diet quality, producing similar levels of stress. Mateus et al. (2019) analyzed development time, dry weight, and viability in the same populations used in this study, and found that tunas and cladodes influenced the organisms in different manners. The individuals in the tuna diet had a development time shorter than the individuals in the cladodes diet. Besides that, the dry weight of the adults and viability larva-pupae were greater in the tuna diet, while in the cladodes diet, the total viability and the viability pupa-adult were greater than in the tuna

*e-mail: rogeriopmateus@gmail.com

Received: December 16, 2020 - Accepted: February 16, 2021 
Table 1. Procrustes ANOVA of shape asymmetry of females and males of Drosophila mojavensis sonorensis. SS = sum of squares; MS = mean square; $\mathrm{DF}=$ degrees of freedom; $\mathrm{F}=\mathrm{F}$ ratio.

\begin{tabular}{|c|c|c|c|c|c|}
\hline & Effect & SS & MS & DF & $\mathbf{F}$ \\
\hline \multirow[t]{6}{*}{ Females } & Diet & 0.0218140 & 0.0010907 & 20 & $27.90^{* * *}$ \\
\hline & Population & 0.8600120 & 0.0215003 & 40 & $550.00^{* * *}$ \\
\hline & Individual (I) & 0.4570800 & 0.0000390 & 11720 & $3.59^{* * *}$ \\
\hline & Side $(S)$ & 0.0025280 & 0.0001264 & 20 & $11.62^{* * *}$ \\
\hline & $\mathrm{I} \times \mathrm{S}$ & 0.1272240 & 0.0000108 & 11780 & $7.11^{* * *}$ \\
\hline & Error & 0.0354000 & 0.0000015 & 23600 & \\
\hline \multirow[t]{6}{*}{ Males } & Diet & 0.0149860 & 0.0007493 & 20 & $17.24^{* * *}$ \\
\hline & Population & 0.9200440 & 0.0230011 & 40 & $529.29^{* * *}$ \\
\hline & Individual (I) & 0.4912880 & 0.0000434 & 11320 & $3.38^{* * *}$ \\
\hline & Side (S) & 0.0006580 & 0.0000329 & 20 & $2.56^{* * *}$ \\
\hline & $\mathrm{I} \times \mathrm{S}$ & 0.1456640 & 0.0000128 & 11380 & $6.96^{* * *}$ \\
\hline & Error & 0.0410040 & 0.0000018 & 22780 & \\
\hline
\end{tabular}

$\mathrm{SS}=$ sum of squares; $\mathrm{MS}=$ mean square; $\mathrm{DF}=$ degrees of freedom; $\mathrm{F}=\mathrm{F}$ ratio. ${ }^{* * *} \mathrm{P}<0.001$.

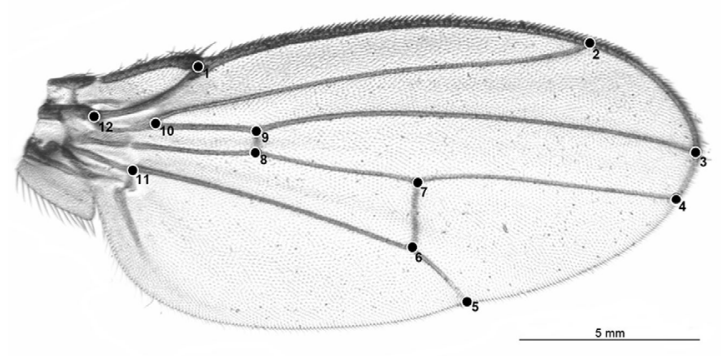

Figure 1. Dorsal view of the right wing of Drosophila mojavensis sonorensis with the position of the 12 type I anatomical landmarks.

diet. Mateus et al. (2019) suggested that the difference in food quality regarding the low concentration of sugar in the cladodes semi-natural diet would be increasing the development time and diminishing the mortality rates of adult flies. This way, the larvae that developed in cladodes and resist the larval phase were thereafter favored in the other phases of development. On the other hand, the larvae that developed faster and in greater size in the tuna diet had more difficulty in the metamorphosis and to emerge. These observations in Mateus et al. (2019) mean that both the higher amount of sugars in tuna and the secondary compounds of cladodes affected the larval development, which is only perceived over the development of the fly. In our case, as the analyzed adults were obtained after the larvae developed in one or the other diet, the amount of sugar and the presence of secondary compounds probably generated similar levels of instability during development.

According to Matzkin et al. (2009), metabolic differences among 12 ecologically diverse Drosophila species most likely reflect the evolution of metabolic adaptations to the ecologically diverse diets utilized by these species, which could have led each species to a unique evolutionary trajectory of metabolic pathways. Therefore, in conclusion,
A

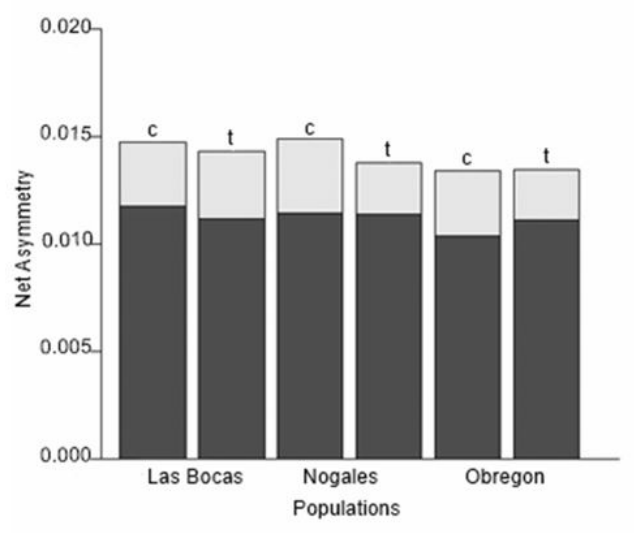

B

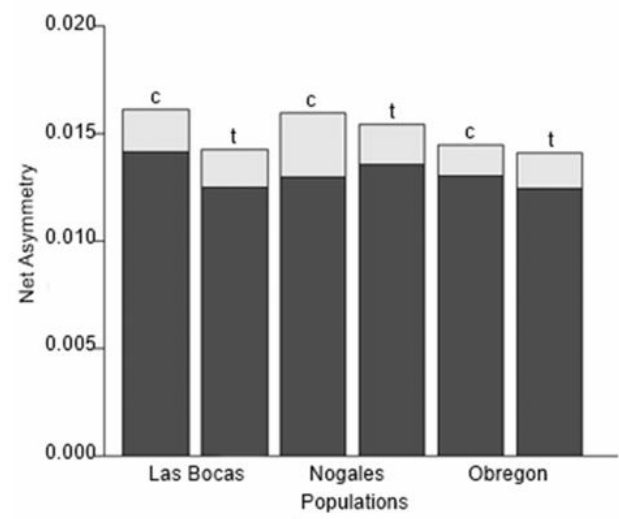

Figure 2. Net Asymmetry level (DA+FA) of Drosophila mojavensis sonorensis, in females (A) and males (B). FA, fluctuating asymmetry (dark gray); DA, directional asymmetry (light gray); c, cladode; t, tuna. 
the use of both diets for $D$. $m$. sonorensis in nature must have generated developmental adaptations during this species evolutionary history, which resulted in similar patterns of instabilities and levels of asymmetry in the presence of the different stressors studied in this work.

\section{Acknowledgements}

We thank Ms. Chloe Furnival for the native English language translation, Dr. Therese Markow for providing the Drosophila stocks and making her laboratory at LANGEBIO available for the development of all experiments involving diets, and Prof. Luis Fernando Segala for critical review of the article. This study was financed in part by the Coordenação de Aperfeiçoamento de Pessoal de Nível Superior - Brasil (CAPES) - Finance Code 001. The authors are also thankful to CAPES for the Master Degree fellowship to JO Prestes and Postdoc fellowship to RP Mateus (number 11732-13-0).

\section{References}

COSTA, M., MATEUS, R.P. and MOURA, M.O., 2015. Constant fluctuating asymmetry but not directional asymmetry along the geographic distribution of Drosophila antonietae (Diptera, Drosophilidae). Revista Brasileira de Entomologia, vol. 59, no. 4, pp. 337-342. http://dx.doi.org/10.1016/j.rbe.2015.09.004.

KLINGENBERG, C.P. and MCINTYRE, G.S., 1998. Geometric morphometrics of developmental instability: analyzing patterns of fluctuating asymmetry with Procrustes methods. Evolution; International Journal of Organic Evolution, vol. 52, no. 5, pp. 1363-1375. http://dx.doi.org/10.1111/j.1558-5646.1998. tb02018.x. PMid:28565401.

KLINGENBERG, C.P., 2011. MorphoJ: an integrated software package for geometric morphometrics. Molecular Ecology Resources, vol. 11, no. 2, pp. 353-357. http://dx.doi.org/10.1111/j.17550998.2010.02924.x. PMid:21429143.

LIMA, C.B.S., NUNES, L.A., CARVALHO, C.A.L., RIBEIRO, M.F., SOUZA, B.A. and SILVA, C.S.B., 2016. Morphometric differences and fluctuating asymmetry in Melipona subnitida Ducke 1910 (Hymenoptera: Apidae) in different types of housing. Brazilian Journal of Biology = Revista Brasileira de Biologia, vol. 76, no. 4, pp. 845-850. http://dx.doi.org/10.1590/1519-6984.01015. PMid:27143063.

MARCHAND, H., PAILLAT, G., MONTUIRE, S. and BUTET, A., 2003. Fluctuating asymmetry in bank vole populations (Rodentia, Arvicolinae) reflects stress caused by landscape fragmentation in the Mont Saint-Michel Bay. Biological Journal of the Linnean Society. Linnean Society of London, vol. 80, no. 1, pp. 37-44. http://dx.doi.org/10.1046/j.1095-8312.2003.00206.x.

MATEUS, R.P., NAZARIO-YEPIZ, N.O., IBARRA-LACLETTE, E., RAMIREZ LOUSTALOT-LACLETTE, M. and MARKOW, T.A., 2019. Developmental and transcriptomal responses to seasonal dietary shifts in the cactophilic Drosophila mojavensis of North America. The Journal of Heredity, vol. 110, no. 1, pp. 58-67. http://dx.doi. org/10.1093/jhered/esy056. PMid:30371801.

MATZKIN, L.M., MUTSAKA, K., JOHNSON, S. and MARKOW, T.A., 2009. Metabolic pools differ among ecologically diverse Drosophila species. Journal of Insect Physiology, vol. 55, no. 12, pp. 1145-1150. http://dx.doi.org/10.1016/j.jinsphys.2009.08.008. PMid: 19698720.

PALMER, A.R. and STROBECK, C., 2003. Fluctuating asymmetry analyses revisited. In: POLAK M., ed. Developmental Instability (DI): causes and consequences. Oxford: Oxford University Press, pp. 279-319.

PALMER, A.R., 1994. Fluctuating asymmetry analyses: a primer. In: T.A. MARKOW, ed. Developmental instability: its origins and evolutionary implications. Dordrecht: Springer, pp. 335-364. vol. 2. http://dx.doi.org/10.1007/978-94-011-0830-0_26.

PFEILER, E., CASTREZANA, S., REED, L.K. and MARKOW, T.A., 2009. Genetic, ecological and morphological differences among populations of the cactophilic Drosophila mojavensis from southwestern USA and northwestern Mexico, with descriptions of two new subspecies. Journal of Natural History, vol. 43, no. 1516, pp. 923-938. http://dx.doi.org/10.1080/00222930802610535.

R DEVELOPMENT CORE TEAM, 2016. [viewed 16 December 2020]. $R$ : a language and environment for statistical computing [online]. Vienna: R Foundation for Statistical Computing. Available from: https://www.r-project.org

ROHLF, F.J., 2015. [viewed 16 December 2020]. TPSDig: Digitize Landmarks and Outlines, Version 2.19 [online]. New York, NY: State University of New York. Available from: http://life.bio. sunysb.edu/morph

SOTO, I.M., CARREIRA, V.P., FANARA, J.J. and HASSON, E., 2007. Evolution of male genitalia: environmental and genetic factors affect genital morphology in two Drosophila sibling species and their hybrids. BMC Evolutionary Biology, vol. 7, pp. 77. http:// dx.doi.org/10.1186/1471-2148-7-77. PMid:17504529.

SOTO, I.M., HASSON, E.R. and MANFRIN, M.H., 2008. Wing morphology is related to host plants in cactophilic Drosophila gouveai and Drosophila antonietae (Diptera, Drosophilidae). Biological Journal of the Linnean Society. Linnean Society of London, vol. 95, no. 4, pp. 655-665. http://dx.doi.org/10.1111/j.10958312.2008.00980.x. 